\title{
基于微信的高校思想政治教育创新机制研究
}

\section{梁宏斌 宋晓雷}

贺州学院

DOI:10.32629/er.v2i12.2262

[摘 要] 在互联网时代, 人们对于电子产品的依赖性越来越大。微信在这个时候作为一个新型的社交软件被广泛利用, 现在已经获得了大众的 喜爱。本文主要是站在高校思想政治教育现状的角度上分析了微信对于高校思想政治教育创新的影响, 以及在微信网络平台上进行高校思想政 治教育创新的有效措施。希望能够给广大高校教师带来一些帮助, 以期得到广大思政教育工作者的指正。

[关键词] 微信; 高校; 思政教育; 创新

\section{引言}

随着网络平台的日渐完善, 微信在普遍高校里都得到了广泛的应用。 一方面, 教师利用微信可以随时随地和学生进行沟通与交流。另一方面, 微信可以满足师生想要了解到外界的任何信息的需求, 以及增长他们的见 识, 提高他们对于外面世界的了解 ${ }^{[1]}$ 。因此, 教师一定要快速掌握微信的各 种运用功能, 以及利用微信技术运用到思想政治教育课堂上来, 切实提高 学生的学习兴趣, 推动思想政治教育课堂的发展。

\section{1 微信的概念及功能}

微信是腾讯公司推出的一款新型社交软件, 用户可以提高手机、电脑 以及各种载体进行下载运用。目前, 微信已经经过了好几次的版本升级很 多功能也趋于完善。微信里的扫码功能可以支持添加好友以及购物付费, 还有摇一摇功能可以找到附近人 ${ }^{[2]}$ 。现在微信技术在我国已经发展得很成 熟, 很多官方平台都在微信上推出了自己的微信公众号去推广自身的平台 形象以及供更多的人去查阅和汶览。

\section{2 微信的特点}

2.1交流富有情感

在没有微信之前, 人们通常都是利用手机短信进行信息的交流, 这种 传输方式因为导致人们要承受很大一部分的短信费并没有得到大家的喜 爱。而且利用这种方式进行交流, 人们看到的只是生硬的文字并没有附带 任何的情感。但是微信的到来改变了这种局面, 作为一种新型的社交软件 解决了这些问题。在使用的过程中, 人们可以发送大量的文字、语音以及 图片和短视频, 丰富了信息的内容还增加了人们聊天的趣味性。这种方式 在一定程度上, 使得人们可以更加明白聊天对方想要表达的意思可以增加 社交的有效性。微信还有一个朋友圈的功能, 让人与人之间的距离大大缩 短还可以实时知道朋友们的生活, 提高了双方的了解。这种社交软件的出 现, 丰富了人们生活的多样性, 拓宽了人们的人际关系交往方式 ${ }^{[3]}$ 。

2. 2 消息推送的及时性

微信上面有很多的公众号, 一般只要公众平台推送了新文章或者新消 息微信可以第一时间展现给用户。这给用户提供了收到消息的及时性以及 第一时间可以看到公众号的更新。现在很多高校以及很多企业都在微信上 开通了公众号, 为了可以让广大用户阅读自己平台的最新资料。我国很多 媒体以及学者和专家都在微信上开通了属于自己个人的公众号, 通过微信 平台把自己最新的信息和资料推送给广大用户完成自己生活以及学术展 示。另外微信这一推送功能可以给广大用户带来了解国家热点时政新闻的 机会和渠道, 满足人们足不出户就能知道天下事的需求。

\section{3 有利影响}

3. 1 完善教育手段

以前互联网信息技术还没有现在这样发展成熟, 教师的教学手段和工
作方式还是比较落后和单一。这种教学方式无法满足大学生对学习的需求, 学生的创新能力也无法得到培养。大学生的思维比较活跃, 也比较喜欢去 接触一些新的事物追求时代的发展脚步。这种教学方式和大学生的特点一 点都不符合, 也和时代发展的特点不相融。长期这样下去, 学生会对思想政 治教育这门课程失去兴趣 ${ }^{[4]}$ 。这个时候高校教师一定要迅速转变教学理念, 革新自己的教学手段终止学生不爱学习思政这门课程的局面。微信的出现 扩大了思政教育的知识面, 还可以增加知识信息的发送方式。对于学生 了解思想政治教育内容的渠道本来就不多, 微信的出现刚刚好把这个渠 道拓宽了, 比如现在比较流行的关注公众号和发送新闻链接都可以让学 生随时随地了解思想政治教育内容。在这个现状下, 思政教育者只有不 断完善自己的教育手段, 丰富教学的内容才能为思政教育工作质量带来 有效的提升。

\section{2增加师生的交流方式}

高校的大学生的认知水平高, 接受新鲜事物的速度也快而微信的方便 和公开及时这些特点正好满足了他们对于社交软件的要求。微信的运用在 不知不觉当中慢慢改变大学生的价值观和思维方式。他们通过网络平台大 胆表现自己以及和网络交流实现信息交流的共享性。微信的广泛使用, 让 大学生可以在网上浏览别人以及自己也被别人发现, 增加每一个人的网络 参与度。另外, 微信的出现不仅丰富了大学生的生活还增加了他们与老师 的交流方式。以前学生除了在课堂上可以见到老师其他时间很难与老师产 生交流, 限制了师生的互动。自微信推出以来, 教师和学生可以随时随地地 进行交流, 既方便又快捷。不管在思政教育的学习中遇到什么问题还是在 生活当中遇到问题, 学生都可以快速获得教师的指导, 避免自己短时间内 出现盲目的状态。教师还可以在微信里关注到学生发的朋友圈了解到学生 最近的思想动向, 对学生及时进行心理辅导和有效交流。

3.3 丰富思政教育形式

对大学生进行思想政治教育是一个长期的过程, 主要的教学内容有个 人理想、道德情操这些, 主要目的是为了帮助学生树立正确的三观以及爱 国情怀。在互联网发展迅速的今天, 网络上充斥着各种信息鱼龙混杂, 让学 生难免受到影响, 给思政教育工作带来很大的冲击。导致思政教育工作无 法体现自己的优越性也不能发挥出自身的价值。因此, 在新时代到来之后, 高校应该对思政教育的手段、形式进行革新。书本上的思政教育内容大多 更新比较慢, 逻辑性也很强如果能够将其与微信平台相结合把书本上知识 转变成学生喜闻乐见的视频或者语音, 那么在很大程度上就可以激发学生 的学习兴趣以及丰富思政教育的形式。学生对于课本上的死知识可能不愿 意去学, 但是如果把这些知识都融合到微信平台里学生学习起来又方便, 完全不受时间地点的限制, 还能和同学老师一起在线交流, 将提高学生对 于思政教育工作的认可度。 


\section{4 有效措施}

4. 1 理性看待微信

高校在运用微信去推广思政教育工作的同时一定要学会树立一个理 性的观念。要用积极的心态去看待微信这一社交平台给高校思政教育工作 带来的任何影响。主动的去了解微信的各种功能以及熟练的操作微信, 发 现任何可以给思政教育工作带来帮助的平台并且进行运用。虽然微信的用 户特别多, 但是高校也不能盲目夸大微信的作用, 而应该在实际的工作中 把这两者进行有效的结合, 充分发挥微信的作用去对高校思政教育工作产 生有利的影响。在使用微信的过程中, 教师首先应该做以身作则, 严谨的发 表自己的言论, 给学生树立一个好的榜样。另外, 要用科学的眼光去看待微 信这个社交软件可能包含的舆论作用, 高校教育者一定要规范学生在微信 平台上的言论, 避免对思政教育工作产生负面的影响, 保证高校思政教育 工作的开展可以顺利进行下去。

4. 2 完善微信运行机制

一个平台要想运行的好必须需要建立一个严格的运行机制。第一要建 立一个强大的保障体系, 能够保证微信平台不能够被黑客利用并且优化内 部的运行环境。制定一系列的法律法规为微信的运转提供强有力的保障, 做好后台的反馈和消息的发布工作保障微信平台推送消息的及时性。第二, 对于微信的每一个用户要进行实名认证, 保证用户的身份是真实有效的。 这样才能确保微信平台的整体平稳运行, 以及高校思政教育的管理有效 性。第三, 要建立微信平台的监管团队, 对不良的信息和违规的操作及时处 理, 以免给思政教育工作带来不必要的麻烦。思政教育工作本来就是为了 提高学生的整体素质而开展的一项活动, 所以在这个过程当中微信平台一 定不能出现一些负面信息去影响思政教育工作的进行。另外思政教育老师 一定要树立崇高的道德理念, 这对思政教育工作的收效起决定性的作用。

4. 3 把握思政教育话语权

自从互联网发展迅速以来, 多元化的价值体系就以及形成, 网上充斥 着各种来历不明的价值观。微信作为高校开展思政教育的新平台, 思政教 育者一定要占据主要地位。第一, 把握住思政教育方向, 微信平台各种信息 不断充斥, 思政教育者一定要坚持社会主义的价值体系, 大力宣扬党的正
确领导方针。第二, 加强对微信平台的监管力度, 网络上的很多东西不一定 适合大学生去学习, 但是如果没有对这些信息进行驱除一定会对高校学生 的思想产生不利的影响。第三, 加强对大学生的思政教育宣传, 很多学生不 知道思政教育是什么, 也不知道它的作用以及重要性。高校思政教育者一 定要加强对学生的思政教育渗透不管是在学校里还是在微信平台, 要积极 向学生阐述思政教育的意义以及重要性, 引导学生重视思政教育课程和学 好这门课程并且告知他们学习思政教育将对他们今后的人生发展起很大 的帮助。第四, 加强和学生的互动, 及时了解学生的思想动向有助于明确今 后思政教育的侧重点。思政教育是一项复杂且需要大量时间的工作, 教育 者一定要摆正工作方向, 了解学生的思想动向以及提高自身的素质才能对 学生的思想教育产生效果。

\section{5 结束语}

综上所述, 随着互联网的迅速发展, 高校的学生对于微信的使用也是 越来越依赖, 这对高校开展思想政治教育工作有利有弊。因此高校在推进 思想政治教育工作的同时一定要分析好自身的发展情况, 正确的看待微信 对高校开展思想政治教育工作带来的两面影响。在推进高校思想政治教育 工作的同时,一定要完善思想政治教育工作的机制、把握思政教育话语权 以及加强微信和思想教育工作的联系。另外, 思政教育是一项耗时长且复 杂的工作, 需要教育者的不断学习和更新教学方式才能取得良好的效果。 只有做到这样, 高校思想政治教育工作的开展才能顺利进行, 学生的思想 道德以及综合素质才能得到提高。

\section{[参考文献]}

[1] 李一聪.基于微信平台的高校辅导员工作创新研究 [D].东北师范大 学,2019(09):58

[2]杨照帅.微信与高校思想政治教育创新的思考 [J]. 智库时 代,2019(03):189-190.

[3]贾娜.运用红色微信创新高校思想政治教育研究 [J].学校党建与思 想教育,2018(24):65-66.

[4]张蓝予.利用新媒体创新高校思想政治教育——以高校微信公众 平台为例[J].世纪桥,2018(12):65-66. 